\title{
Designing Situations
}

\author{
Toni Robertson \\ Faculty of Engineering and Information \\ Technology \\ University of Technology, Sydney \\ PO Box 123, Broadway, NSW, AUSTRALIA \\ Toni.Robertson@uts.edu.au
}

\begin{abstract}
This paper extends the analytic framework Suchman used in Plans and Situated Actions by using it as a tool in the design of interactive, immersive environments that rely on human movement as input. We describe the historical and methodological background to Suchman's framework and the impact of her analysis on the development of HCI and related fields. We provide two examples of its use to support prototype evaluation, design reflection and generative and iterative design. Suchman's recognition that computers act on the basis of resources within their situations, just as people act in accord with the resources of theirs, broadens our focus from the design of interfaces to the design of situations within which interaction between people and computers can occur. The tool, and the methodological and theoretical commitments embedded within it, contribute to the design of emerging technologies and to current discussions about approaches to design within shifting paradigms of HCI.
\end{abstract}

\section{Author Keywords}

design tool, interaction design, interactional resources, situated action, Suchman, Plans and Situated Actions

\section{ACM Classification Keywords}

H5.m. Information interfaces and presentation (e.g., HCI): Miscellaneous.

\section{INTRODUCTION}

The view of action that ethnomethodology recommends is neither behaviouristic, in any narrow sense of that term, nor mentalistic. It is not behaviouristic in that it assumes that the significance of action is not reducible to uninterpreted bodily movements. Nor is it mentalistic, however, in that the significance of an action is taken to be based, in ways that are fundamental rather than secondary or epiphenomenal, in the physical and social world. The basic premise is twofold: first, that what traditional behavioural sciences take to be cognitive phenomena have an essential relationship to a publicly available, collaboratively organised world of artefacts and actions, and secondly, that the significance of artefacts and actions, and the methods by which their significance is conveyed, have an essential relationship to their particular, concrete circumstances. Suchman, L. (1987). Plans and Situated Actions, p. 50, our emphasis.

OZCHI 2009, November 23-27, 2009, Melbourne, Australia. Copyright the author(s) and CHISIG

Additional copies are available at the ACM Digital Library (http://portal.acm.org/dl.cfm) or ordered from the CHISIG secretary (secretary@chisig.org)

OZCHI 2009 Proceedings ISBN: 978-1-60558-854-4
Lian Loke

\author{
Faculty of Engineering and Information \\ Technology \\ University of Technology, Sydney \\ PO Box 123, Broadway, NSW, AUSTRALIA \\ Lian.Loke@uts.edu.au
}

It is over twenty years since Suchman first published Plans and Situated Actions (P\&SA). The book quickly assumed classic status and continues to be highly influential in the evolving field of human computer interaction (HCI), as well as computer supported cooperative work (CSCW), participatory design (PD) and related areas. In a discussion of the impact of P\&SA on the development of HCI, Carroll (2003) commented that it "has been reconstructed as an emblem for sweeping currents of paradigmatic development in HCI, many of which Suchman herself subsequently helped to launch" (p. 273). He makes the crucial point that it is the reconstructions of $\mathrm{P} \& \mathrm{SA}$ that may be its most significant contributions to our understanding of HCI.

More recently, Harrison, Tatar and Sengers (2007) suggested that a number of disparate approaches such as PD, situated action, ethnography and critical design might be usefully understood as united in a coherent third wave, or paradigm, in HCI.

Over the last few years, the authors of this paper have become increasingly aware that a third paradigm has been discussed in corners and cafes with much head nodding at the CHI conference ... Our name for this is "situated perspectives".

This is a fitting name given Suchman's central involvement in the various approaches that are united in this third paradigm.

Harrison et al. (2007) identify the original paradigm of $\mathrm{HCI}$ as stemming from engineering and human factors with a focus on optimising man-machine (sic) fit. The second stems from cognitive science, with an increased emphasis on cognitivist theory and on what is happening, not only in the computer, but assumed to be happening simultaneously in the human mind. They define and explore their third paradigm, situated perspectives, describing its principles, comparing it to the two other paradigms and considering the role of design within each. The central focus placed on meaning and meaning construction is the first principle of the situated perspectives paradigm. The understanding of meaning the authors articulate is "irreducibly connected to the viewpoints, interactions, histories, and local resources available to those making sense of the interface" (ibid) which they acknowledge as the understanding of meaning used by Suchman in P\&SA.

Harrison et al. (2007) suggest that each paradigm of HCI has different goals with respect to design. They cite Wright, Blythe and McCarthy's (2006) discussion of how the notion of what design is, and how to approach it, 
varies in each. In the situated perspectives paradigm "design is an element of enquiry. Since interaction is seen as an element of situated action in the world, the understanding or construction of the situation is the core of the design" (Harrison et al., 2007, our emphasis). We can see here why the situated perspectives paradigm includes those approaches where situated action is a given, such as PD, participatory action research, ethnography and other studies of practice, and valuesensitive or critical design. These approaches share the use of design tools, techniques and methods that seek always to ground the design, in various ways, in the real world contexts of embodiment, situated meanings, values and social issues. Harrison et al. (2007) recognise that in designing technology we are also constructing the situations in which people and technology can act together; but, most importantly, they then move this recognition to the focus of our attention as designers.

In this paper we seek to contribute to this important paradigmatic development in HCI with a new reconstruction of $\mathrm{P} \& S A$ that extends its insights directly into the design of emerging technologies. Specifically, we describe how we have used and extended the analytic framework Suchman developed as both a prototyping and design tool; in our case, in the design of interactive, immersive environments that rely on various kinds of sensors to enable human movement as input. But it is not our aim here to present a new design tool as such. Dourish and Button (1998) observed that as many within HCI and CSCW have taken up various aspects of Suchman's work "they have also taken on, perhaps unwittingly, an ethnomethodological influence" (p. 402). Our aim here is to explicitly ground our use of Suchman's framework, including the various influences, philosophic commitments, histories and perspectives that give it meaning, within the developing situated perspectives paradigm of HCI. We do this by beginning our discussion with a section contextualising P\&SA, including some background of its original publication and some of the responses to it that have been important to the development of HCI. From there we consider Suchman's analytic framework, paying particular attention to the ethnomethdologically-informed understanding of interaction as mutual intelligibility that she articulated in P\&SA. Two examples are discussed of the extension of the Suchman framework into a design tool that supports evaluation, design reflection and generative and iterative design. We end this paper with a reflection on designing situations and the need for new design tools to work with new technologies within developing paradigms.

\section{BACKGROUND}

Suchman (2007, chapter 1) explains that her original study focused on assumptions about interactivity and human conversation that were prevalent within artificial intelligence (AI) during the early to mid 80's. She considered these in the light of findings from studies of human conversation within sociology, especially ethnomethodology and conversation analysis. She was, at the time, a research intern at Xerox Palo Alto Research Centre (PARC) working on her doctoral research in cultural anthropology. Her project involved a close study of various people attempting to use the prototype interface that was intended to resolve problems that Xerox's customers were encountering when using a newly released photocopier. The basis for the design of the new interface was the planning model of human action that prevailed in the AI research community. This view maintained that human actions were determined by plans that were considered to be some kind of internal, "cognitive control structures that universally precede and determine actions" (ibid, p. 13). Suchman wrote:

More specifically, my colleagues were engaged with initiatives in 'knowledge representation', which for them involved, among other things, representing 'goals' and 'plans' as computationally encoded control structures. When executed, these control structures should lead an artificially intelligent machine imbued with the requisite condition-action rules to take appropriate courses of action (p. 10).

But the new interface introduced its own problems. Essentially P\&SA is Suchman's analysis of the reasons why these new problems emerged, along with extensive discussion of the perspectives and disciplinary backgrounds that made her analysis possible. In particular, these perspectives and disciplinary backgrounds profoundly reject any understanding of human communication as the simple exchange of inherently meaningful messages. This is essentially the sender/receiver model of communication that is common within the formal, mathematical theories of communication used within AI and fundamental to some of its central concepts such as plans and goals.

The crucial insight in Suchman's analysis was to take seriously the computer as a conversation partner in human computer interaction. She recognised that, just as in people's interactions with each other, interactions between people and technologies needed to achieve 'mutual intelligibility' between the participants in the interaction, if that interaction was to be successful.

Humans dynamically coconstruct the mutual intelligibility of a conversation through an extraordinarily rich array of embodied interactional competencies, strongly situated in the circumstances at hand (the bounds and relevance of which are, in turn, being constituted through that same interaction). I accordingly adopted the strategy of taking the premise of interaction seriously and applying a similar kind of analysis to people's encounters with the machine to those being done in conversation analysis. The result of this analysis was a renewed appreciation for some important differences - more particularly asymmetries - between humans and machines as interactional partners and for the profound difficulty of the problem of interactive interface design. (Suchman, 2007, pp. 10-11).

By analysing the interaction between the photocopier and those using it, Suchman made visible the ways in which this conversation was constrained and undermined by the limited resources available, to both the photocopier and its users, to interpret each others' actions. In so doing she demonstrated the inadequacies of the AI planning model of human action to model actual human behaviour and dealt an unanswerable refutation to some of the fundamental assumptions, assertions and expectations of both $\mathrm{AI}$ research at the time and the developing discipline 
of Cognitive Science. But, with the same analysis Suchman also made a profound and ongoing contribution to the then new field of HCI (the first CHI conference was held in 1982; CHISIG was established in 1984).

When P\&SA was published in 1987, the second paradigm identified by Harrison et al. (2007) was becoming dominant in HCI. This paradigm stems from cognitive science and is defined by an understanding of human cognition as a process of internal symbol processing. The metaphor of the information processor is used to couple the human mind and computer. In this approach interaction is understood as information exchange, just as it was in AI and indeed most parts of computer science at the time. Cognitive Science potentially offered the new field of HCI a theoretical foundation that might explain, predict and prevent usability design problems and enable a discipline to develop.

But there have always researchers involved in HCI and related fields who recognized that reducing people to information processors excluded too much that was essential and defining of human action, including bodies, social issues, contexts, culture, values and ethics, to name just the most obvious. Various situated approaches were being articulated in HCI and related areas and PD was developing strongly in Scandinavia. P\&SA was warmly welcomed as, to recall Carroll's words, "an emblem for sweeping currents of paradigmatic development in HCI" (2003, p. 273).

Carroll (2003) acknowledged the role P\&SA had played in moving HCI "to a place where ethnographic workplace studies and worker participation in design are standard engineering practices" (p. 278). Dourish and Button (1998) argued that P\&SA also introduced ethnomethodology as a "favoured approach" within HCI (p. 395). They emphasised the distinction between ethnography and ethnomethodology, recognising the first as a "field of investigative fieldwork and analysis" frequently used by ethnomethodologists, and ethnomethodology itself as "a particular analytic orientation to the practical issue of the problem of social order" and a critical approach to, and within, sociology.

[P\&SA] is very widely read and cited in the HCI literature, and firmly established the relevance of sociological and anthropological reasoning for the problem of humancomputer interaction. As such, the book and the argument it puts forward have come to occupy an almost iconic position within the field . . . her argument and analysis drew strongly on the ethnomethodological tradition, and introduced it to the HCI community. The HCI community has never recovered (pp. 405-406).

It is perhaps in the field of CSCW that P\&SA had its greatest impact on technology design. Fitzpatrick, Kaplan and Mansfield (1996), for example, identified situated action as among the "givens" in CSCW (p. 334). Plowman et al. (1995), in a major review of workplace studies in the CSCW literature, noted: "Suchman's (1987) classic study is considered essential reading for sociologists, system designers and students of CSCW alike and has been much cited" (p. 315). As well, intensive discussions of P\&SA and its implications generated two special editions of journals at the intersection of the cognitive and social sciences. The first, Cognitive Science (7 (1), 1993) contained a major critique from the cognitivist perspective (Vera and Simon, 1993), along with a number of rejoinders, including from Suchman herself, as well as those who would go on to incorporate situated action in their own work within cognitive science, such as Phil Agre and Bill Clancey. A second collection of responses to P\&SA was published in the Books and Ideas section of the Journal of the Learning Sciences (12(2), 2003). P\&SA is described there as a "harbinger of a paradigmatic shift that was to take place within the cognitive science community in the decade and a half to follow" (Koschman, 2003, p. 257).

\section{All human actions are situated actions}

P\&SA is as notable for the various debates over the nature of its impact and the misreadings and controversies over its contents as it is for that content itself. Here, for the sake of clarity in the remainder of this paper, we will briefly address the most common misreading which appears to allow for some human actions to be situated and some not to be. It stems from a reading of planned and situated as different kinds of action (Suchman 2007, p. 16). These are then set up as oppositions predetermined actions as opposed to spontaneous ones; or sometimes, actions independent of context opposed to actions determined by context. Neither of these is anything like the meaning Suchman intended. She wrote:

\footnotetext{
However planned, purposeful actions are inevitably situated actions. By situated actions, I mean simply actions taken in the context of particular, concrete circumstances . .

The circumstances of our actions are never fully anticipated and are continuously changing around us. As a consequence our actions, although systematic, are never planned in the strong sense that cognitive science would have it. Rather, plans are best viewed as weak resources for what is primarily ad hoc activity (2007, p. 26).
}

The point is that all human actions, whether predetermined, spontaneous or anywhere in between, are situated actions. Indeed we can have no other kind. The use of the term highlights the fact that "every course of action depends in essential ways upon its material and social circumstances" (p. 70). That is, no action can ever happen outside of its context; this is a fundamental fact of the physical world and human embodiment in it.

But Suchman not only emphasised that all human action is situated. By taking computers seriously as partners in interaction, she recognised that the actions of interactive technologies are also situated actions. We act in accordance with the constraints and opportunities of our situations, computers act in accordance with the constraints and opportunities of theirs.

\section{Suchman's analytic framework}

The aim of the analysis was to find the sense of "shared understanding" in human-machine communication. More particularly, I wanted to compare the user's and the system's respective views of the interaction, over a sequence of events (p. 123).

Suchman's framework is actually remarkably simple. Our aim in this background section is to demonstrate that the understanding of interaction behind it is not simple at all, 
particularly for those of us working within technology design environments where sender/receiver models of communication still dominate. Suchman's account of interaction reveals an ongoing negotiation of shared meaning and the interpretive work and interaction resources required to achieve it:

The practical problem with which the designer of an interactive machine must contend is how to ensure that the machine responds appropriately to the user's actions. As in human communication, an appropriate response implies an adequate interpretation of the prior action's significance. And as in human communication, the interpretation of any action's significance is only weakly determined by the action as such. Every action assumes not only the intent of the actor, but the interpretive work of the other in determining its significance. That work, in turn, is available only through the other's response. The significance of any action and the adequacy of its interpretation are judged indirectly, by responses to actions taken, and by an interpretation's usefulness in understanding subsequent actions. It is just this highly contingent process that we call interaction (Suchman, 2007, p. 126).

The power of Suchman's original analysis stems from the series of analytic moves she made. Firstly, she considered the computer, quite literally, as a conversation partner in the interaction.

I adopted the methodological strategy of applying analytic techniques and insights from the study of human interaction to see what would happen if we took the metaphor of human-computer interaction seriously (p. 22).

Secondly, she conceptualised human computer interaction using insights from studies of human conversation within sociology, especially ethnomethodology and conversation analysis. Most importantly, she used an ethnomethodological view of action (see opening quote in this paper) that meant that if the computer was a partner in the interaction, then the computer's actions were situated in exactly the same way as the human participants' actions were; that is to say, for both the human participants and the computer "every course of action depends in essential ways upon its material and social circumstance" (p. 70). But the situations are very different because the resources available to the people were very different to those available to the computer.

For purposes of the analysis, and without ascribing intent in any way, I will assume that the machine is behaving on the basis of resources provided by "its" situation, the user in accord with the resources of hers. The aim of the analysis then is to view the organisation of human-machine communication, including its troubles, in terms of constraints posed by asymmetries in the respective situation resources of human and machine (p. 125).

Finally, Suchman created a analytic framework that rendered visible the "respective situation resources of human and machine" in a way that exposed just where the problems and successes of the interaction between people and the new photocopier interface lay. In essence Suchman's analytic framework is a table divided into two halves, one for people and one for the technology. Each side has two columns that describe the different kinds of resources for interaction available within the respective situations of the users and the computer. The framework is shown in Figure 1.

\begin{tabular}{c|c|c|c}
\multicolumn{2}{c|}{ The User } & \multicolumn{2}{c}{ The Machine } \\
\hline $\begin{array}{l}\text { Actions not } \\
\text { available to } \\
\text { the machine }\end{array}$ & $\begin{array}{c}\text { Actions } \\
\text { available to } \\
\text { the machine }\end{array}$ & $\begin{array}{c}\text { Effects } \\
\text { available to } \\
\text { the user }\end{array}$ & $\begin{array}{c}\text { Design } \\
\text { rationale }\end{array}$ \\
\hline
\end{tabular}

Figure 1. Suchman's analytic framework

The two columns on the left are for the users' actions, one for the actions available to the machine and one for those that are not available to the machine but available to the human participants (both users and observers). The two on the right are for the machine's situation, one for the effects, or actions, of the machine that are available to the user and one for the computer equivalent of user actions not available to it that Suchman called the "design rationale". This has been misleading for many readers within HCI who will be more familiar with the later use of the term to name the motivations, justifications, tradeoffs and reasoning behind design decisions (Moran and Carroll, 1996). Suchman used the term to refer to the "internal" resources the computer has for interpreting user actions that have been provided by programmers such as look-up tables, program code, etc. That is, the "logic built into the system for why, given a particular user action, the machine behaviour constituted an appropriate response" (Suchman, personal communication).

When a sequence of human computer interaction is mapped onto the framework, the centre two columns represent what is mutually available to the machine and its users - that is, the human computer "interface". The outer columns contain the respective resources for interpretation available to the user/s on one side and of the designers (via the computer) on the other. Put another way, the framework makes visible in a systematic and structured way the relevant contextual resources available to the participants (human and machine) to negotiate shared meaning during each stage of the process of interaction. Suchman recognized "that this comparison located precisely the points of confusion, as well as the points of intersection or "shared understanding" (p. 124).

Suchman's analytic framework makes visible the structure of human computer interaction so that it could be inspected and evaluated. Yet we were surprised to find little evidence of its use outside of P\&SA. Some exceptions are Frohlich and Luff's (1989) use of the conversation analysis approach to inform the management of local dialogues in a demonstration system to give welfare rights advice to members of the public. Douglas (1995) used Suchman's framework in the design and evaluation of a simulation program for learning about the cardiovascular system.

\section{USING SUCHMAN'S FRAMEWORK AS A DESIGN TOOL}

Over the past seven years we have been engaged in a broad programme of research about human movement as direct input into sensing technologies (eg. Robertson, Mansfield and Loke, 2004, 2006; Larssen, Loke, Robertson and Edwards, 2004; Loke, Larssen, Robertson and Edwards, 2004, 2007; Loke and Robertson, 2005, 2008a and b). These are novel and complex technologies 
and in the early stages of this research we sought existing design tools and techniques that might assist us in orienting ourselves to both the design and usability issues belonging to these emerging technologies. We used Suchman's framework because it gave primacy to the situations in which interaction, both successful and otherwise occurred. Our approach to design, like that of Harrison et al.'s (2007) third paradigm of HCI, puts "the understanding and construction of the situation" at its core. So a framework that we could use to reveal the resources of the system's "situation" alongside those of the users offered us the potential to design resources for both. In particular, we could design resources to address the asymmetries in achieving mutual intelligibility when humans and machines are interactional partners. In the remainder of this section we discuss two examples of our use of Suchman's framework as a design tool; firstly as an evaluation tool and secondly as a very flexible, generative interaction design tool.

\section{Evaluating a prototype}

We evaluated two Sony Eyetoy ${ }^{\mathrm{TM}}$ games as a grounding exercise to identify a range of design issues that we could use to inform future projects. Detailed discussions of this study can be found in Larssen at al., (2004) and Loke et al., (2007). In summary, eight participants were recruited to play two pre-selected games. Participants were filmed from two angles. One view captured a projection of the participant's mirror image in the gamescape; the other view captured from front-on the participant's full body whilst playing.

The video tapes were then analysed using four existing frameworks and approaches, drawn from different disciplines that relate to interaction and movement. The aim was to explore the relationships between bodily actions and the corresponding responses from technology from the four different perspectives provided by these frameworks and approaches. Suchman's framework was used to reveal the structure of the interaction design of the Eyetoy $^{\mathrm{TM}}$ games. We divided the column on Actions not available to the machine in order to provide space to map the user activities to their bodily movements at each stage of the game. We renamed the Design rationale column Game context to clarify that it contained the internal resources available to the computer to organise its side of the interaction, that is the logic dictating the state changing behaviour of the system and its responses to user input.

Figure 2. shows a fragment of the game play of a game called Beat Freak. In this game there are four speakers one in each corner of the screen. Periodically, one or more CDs fly out from the centre of the screen towards one of the corners. The game requires the player to move their hand over a speaker at the same time as a CD flies across it. The active areas for input in this game are the circular zones represented by the speaker. When a CD is moving, for example, to the upper left corner, the area represented by the speaker becomes active for a specific time period in which the user's movement can be registered. As in Suchman's original framework, the two greyed columns show what is mutually available to the machine and its users - that is, the human computer "interface" that needs to support whatever interaction is required to successfully play the game.

The framework was valuable in three key ways. Firstly, it made clearly visible the asymmetries between the resources available to the user and to the machine for perception of action. The machine perception is limited to motion detection over a narrowly defined spatial area within a given time period that is directed by the game context and mapped to a particular game event. Players, as would be expected, have much richer resources available to them. Secondly, and very differently from Suchman's original photocopier, the game itself is providing many of the user resources through the rich

\begin{tabular}{|l|l|l|l|l|}
\hline \multicolumn{2}{|c|}{ The User } & \multicolumn{2}{c|}{ The Machine } \\
\hline \multicolumn{2}{|c|}{ Actions not available to the machine } & $\begin{array}{l}\text { Actions available to } \\
\text { the machine }\end{array}$ & $\begin{array}{l}\text { Effects available to the } \\
\text { user }\end{array}$ & \multicolumn{1}{c|}{ Game context } \\
\hline $\begin{array}{l}\text { Awaiting start of } \\
\text { game. }\end{array}$ & $\begin{array}{l}\text { Ready position: Standing } \\
\text { feet hip width apart, both } \\
\text { hands held at navel, closed } \\
\text { fist. }\end{array}$ & $\begin{array}{l}\text { Calibrated image of } \\
\text { user }\end{array}$ & $\begin{array}{l}\text { Gamescape } \\
\text { Visualtext: “Countdown" }\end{array}$ & Game starts \\
\hline $\begin{array}{l}\text { Attempt to hit CD as } \\
\text { it intersects speaker } \\
\text { cone. }\end{array}$ & $\begin{array}{l}\text { Reach out to upper front left } \\
\text { with left arm, fingers spread. }\end{array}$ & $\begin{array}{l}\text { (no machine input } \\
\text { besides image of user) }\end{array}$ & $\begin{array}{l}\text { CD emerges from centre } \\
\text { and travels to upper left } \\
\text { speaker. }\end{array}$ & $\begin{array}{l}\text { Event - CD } \\
\text { launched }\end{array}$ \\
\hline $\begin{array}{l}\text { Successful strike on } \\
\text { the beat. }\end{array}$ & $\begin{array}{l}\text { Left hand intersects speaker } \\
\text { cone simultaneously with } \\
\text { CD. }\end{array}$ & $\begin{array}{l}\text { Motion detection over } \\
\text { area representing } \\
\text { upper left speaker } \\
\text { cone }\end{array}$ & $\begin{array}{l}\text { Speaker vibrates and CD } \\
\text { shrinks. Sound of cymbal } \\
\text { clash. }\end{array}$ & $\begin{array}{l}\text { Event- } \\
\text { successful strike }\end{array}$ \\
\hline $\begin{array}{l}\text { Return to ready } \\
\text { position. }\end{array}$ & $\begin{array}{l}\text { Lower left arm to ready } \\
\text { position. }\end{array}$ & $\begin{array}{l}\text { (no machine input } \\
\text { besides image of user) }\end{array}$ & $\begin{array}{l}\text { Gamescape with } \\
\text { animated characters } \\
\text { dancing along }\end{array}$ & $\begin{array}{l}\text { Pending next } \\
\text { event }\end{array}$ \\
\hline $\begin{array}{l}\text { Waiting for next } \\
\text { event, rhythmic sway } \\
\text { to music. }\end{array}$ & Shifting weight side to side. & $\begin{array}{l}\text { (no machine input } \\
\text { besides image of user) }\end{array}$ & $\begin{array}{l}\text { Gamescape with } \\
\text { animated characters } \\
\text { dancing along }\end{array}$ & $\begin{array}{l}\text { Pending next } \\
\text { event }\end{array}$ \\
\hline
\end{tabular}

Figure 2. Fragment of interaction with Eyetoy ${ }^{\mathrm{TM}}$ game mapped to Suchman's Analytic Framework 
game effects that are available to the user. These include the animated visual display, the use of sound and the general narrative of the games itself that gives meaning to the really very simple events within it. At the end of P\&SA, Suchman suggested finding ways of using computationally available resources to compensate for the machine's lack of access to the user's situation as one strategy designers could use to reduce the problems of interaction design (2007, p. 178). Expressed in Suchman's terms, the game provided the resources that people needed to shape their own actions to achieve "points of intersection or shared understanding" enabling successful interaction. Finally, and most importantly for our wider of programme of research, the framework enabled us to describe the movements of users as actions occurring in context, without losing their essential situated aspects. This meant that it could function as a valuable tool to support design reflection and learning about what mutual understanding between humans and computers might look like and how it could be supported.

\section{Designing interaction}

Every human tool relies on, and materialises, some underlying conception of the human activity it is designed to support (Suchman, 2007, p. 31)

In our second example, we made a more varied and extensive use of Suchman's framework in the design and development of Bystander, a multi-user, immersive, interactive environment intended for public display in a museum or art gallery. Bystander was designed to make available various kinds of heritage collections in novel and culturally responsible ways. Our role in its design was to investigate how the methods, tools and techniques, developed to support participative approaches within traditional computing design environments, might be made both useful and relevant in designing the potential interaction and experiential opportunities within a multiuser, immersive, interactive environment. This was a large project and more detailed discussions of the full range of activities within it can be found in Robertson et al., (2004, 2006) and Loke and Robertson (2005, 2008b). We limit our discussion here to the use of Suchman's framework within it.

Essentially we used it as a working tool for iterative design and prototyping. The major conceptual move was made possible by our realisation that, as designers, we were the ones designing the machine's "situation". We could design this technology by making decisions about the resources that were available to the system within its "situation". We could "backward engineer" the framework, using it as a kind of spreadsheet that enabled us to ask "what if?" questions about, for example, what user actions the system would be able to perceive and therefore, what kinds of sensing technologies we used; how this input would be interpreted by the system and how it might be mapped onto the system responses. We could decide what the various different machine states were, as well as what events would change them. We could think about what kind of conversation we wanted people to be able to have with the technology and design the resources to support the interaction accordingly. We could, in essence, design this technology by making decisions about the resources that were available to the system within its "situation", including those it could make available to its users in theirs. The framework allowed us to keep track of the myriad design decisions, both big and small, that needed to be made throughout the design process so that we could systematically match and resource audience and system behaviour, actions and responses, from both the user and system perspectives.

Most importantly, the results of our user research particularly the scenarios and personas we had developed from it - were mapped very directly to the left-hand column of the framework to become actions not available to the machine. In this way we were able to develop a script, based on our user research, and then populate the rest of the framework accordingly through various rounds of prototyping and evaluation. We could also add more columns whenever we had specific aspects of the design on which we wanted to focus.

Figure 3. (below) shows a fragment of an early stage of the interaction script developed during the design of Bystander. The fragment shows two examples of the patterns of user behaviour we had observed; slow-moving contemplative visitors and head-pokers, visitors who just poke their heads into an exhibit space and then move on. The left-hand column includes these patterns along with scenarios involving the personas matching them. We could then map these scenarios to the effects we wanted the system to make available to exhibit visitors at different stages. In the second row of figure 3, for example, the cell, Effects available to the user still contains a design question because we had not yet decided whether head-pokers, who just look in quickly and then go away, would count as an event to which the system needed to respond. User evaluation of an early prototype demonstrated that a system response to headpokers produced a confusing experience for those remaining in the environment so in the final system this pattern of user behaviour remained unavailable to the technology. Other design questions were mapped in the right-hand column and as they were resolved, the effects available to the user could also be evaluated and resolved.

We later added an extra column to the left-hand side of the table (not shown here due to space restrictions) where we mapped the time each user activity might take, again from user research. In this way we were able to build up a 45-minute script to use during evaluation of the developing prototypes. We added another column, also not shown here, which mapped each row to a set of spatial schemas showing where particular visitors might be at any one time and how they would move about the space. In its final form we used the framework as a script that a number of users could follow as a way to evaluate, in real time, full-size prototypes of the developing immersive environment. The design questions in the right-hand column were answered during evaluation including questions about what counted as an event that would trigger a state change, what that change might be and, most importantly, how this would map to effects that were available to the user. A detailed discussion of the 


\begin{tabular}{|c|c|c|c|c|}
\hline \multicolumn{2}{|c|}{ The User } & \multicolumn{3}{|c|}{ The Machine } \\
\hline $\begin{array}{c}\text { Actions not available to } \\
\text { the machine }\end{array}$ & $\begin{array}{l}\text { Actions available to } \\
\text { the machine }\end{array}$ & $\begin{array}{l}\text { Effects available to } \\
\text { the user }\end{array}$ & Internal 'logic' & Design Questions \\
\hline $\begin{array}{l}\text { Slow-moving, } \\
\text { contemplative visitors. } \\
\text { Betty and Val enter room } \\
\text { together and stand fairly } \\
\text { still looking around with } \\
\text { heads turning. }\end{array}$ & $\begin{array}{l}\text { Two figures enter } \\
\text { room together. } \\
\text { Some motion within } \\
\text { a small area }\end{array}$ & $\begin{array}{l}\text { State } 1 . \text { Flock } \\
\text { coherent presentation } \\
\text { on wall, w2. }\end{array}$ & \multicolumn{2}{|c|}{$\begin{array}{l}\text { System in state } 1 \text {. What is that behaviour? } \\
\text { What does the system consider "still'? Standing } \\
\text { absolutely still may realistically translate to talking on } \\
\text { the phone or to a companion. Watching the display } \\
\text { may translate to slow, peaceful, gentle body } \\
\text { movements and locomotion within a very small area. }\end{array}$} \\
\hline $\begin{array}{l}\text { Head-poker. } \\
\text { Young teenager enters, } \\
\text { blocked by Betty and Val, } \\
\text { so leaves. }\end{array}$ & $\begin{array}{l}\text { Figure enters room, } \\
\text { stops just inside } \\
\text { doorway then exits. }\end{array}$ & Is there a change? & \multicolumn{2}{|c|}{$\begin{array}{l}\text { Has this person been detected? May want dead zone at } \\
\text { entry. } \\
\text { If their entrance and quick exit affects the system only } \\
\text { those already there will experience the shift. Is this the } \\
\text { behaviour we want? }\end{array}$} \\
\hline $\begin{array}{l}\text { Betty and Val decide to } \\
\text { stay and watch more, walk } \\
\text { towards centre. }\end{array}$ & $\begin{array}{l}\text { Two figures move } \\
\text { towards centre. }\end{array}$ & $\begin{array}{l}\text { Does the state } \\
\text { change? }\end{array}$ & \multicolumn{2}{|c|}{$\begin{array}{l}\text { Is this sufficient movement to trigger a state shift to } \\
\text { state } 2 \text { ? } \\
\text { What is state } 2 \text { behaviour? }\end{array}$} \\
\hline $\begin{array}{l}\text { They watch the flock, } \\
\text { turning slowly taking } 1 \text { or } 2 \\
\text { steps each way. }\end{array}$ & $\begin{array}{l}\text { Detection of } 1-2 \\
\text { figures at centre } \\
\text { moving slowly in a } \\
\text { small area. }\end{array}$ & $\begin{array}{l}\text { Flock behaviour } \\
\text { depends on answers } \\
\text { to design questions. }\end{array}$ & \multicolumn{2}{|c|}{$\begin{array}{l}\text { Does position of visitors matter to the room? If so } \\
\text { how? } \\
\text { Will the system differentiate two people close } \\
\text { together? }\end{array}$} \\
\hline
\end{tabular}

Figure 3. Fragment of interaction with Bystander mapped to Suchman's Analytic Framework

development and use of this script in the design of Bystander can be found in Loke and Robertson (2008a).

There are a number of points to make about the use of Suchman's framework as an interaction design tool in this project. We were designing a novel and complex system as part of a larger design team that included artists, programmers, exhibition designers, graphic designers and sound engineers. Extending Suchman's framework in this way provided a design tool that acted as a crucial communication resource for the team and supported ongoing, iterative design reflection and decision-making. It provided a very direct and accountable link between our user research and the design and development process of the system and its behaviour. Its framing of interaction in terms of resources available to both user and machine enabled the designers to explore and map the relationship between the movements of users and the system response. It also proved valuable for making explicit our design assumptions about user behaviour, particularly the meaning and interpretation of movement that eventually became embedded in the system. The framework was also incredibly flexible when used as a design tool. We could add and delete columns according to what we needed to understand at any particular point of time. Suchman's original analytic framework made visible the "respective situation resources of human and machine" in a way that exposes where the problems and successes of the interaction between people and the machine interface lay. Using it as a design tool, as its use in this project showed us, offers the power of that analysis to the designer during the design process.

\section{DISCUSSION}

In this paper we have revisited the analytic framework that made possible the profound insights and contributions of P\&SA, setting out the methodological and philosophical commitments behind its use and briefly describing the context of its development and initial publication. We have reminded our readers that Suchman has provided a tool to reveal and help us think about the respective situations of interactive technologies and those who use them. We provided examples of how we used and extended Suchman's framework as a design tool in the design of interactive, motion-sensing technologies and noted some of the contributions it made to our design methods and processes.

In P\&SA, Suchman used the term "perceive" in relation to the photocopier's access to the users' actions that actually changed its state. When using Suchman's framework as a design tool, we take seriously the question of what, exactly, is available to "perceiving" technologies. We do not mean this in the sense of machine perception as a technical field within AI and computer science. Instead we mean it in the phenomenological sense; that it is our perception that enables us to have a world and the kind of world that it is (Merleau-Ponty, 1962). While Suchman's photocopier "perceived" trays moving in and out, buttons being pressed, doors opening and closing and so on, current technologies have a much greater range of input devices available to them to "perceive" much more of the worlds of their users. Designers now have much wider options available to them to design the worlds of technologies that are accessible to people.

For us, one of Suchman's pivotal insights was the recognition that the machine has a situation too. Irrespective of whether it is a photocopier or a complex immersive environment, its actions are as situated as ours are. This is why we have included such a detailed discussion of P\&SA and situated action to accompany our discussion of the use of Suchman's framework in design. We need to understand what it is we are actually designing when we design the potentials for interaction between people and technologies. As designers we can approach designing as the "understanding or construction of the situation" (Harrison et al., 2007), both the users' 
situations and the machine's. In designing the situation of a particular interactive technology, we are designing the resources it has for acting in that situation, including its access to the situations of those with whom it will interact. We need to provide points where the situations of the user and the technology can meet. Suchman's important contribution - to take seriously the computer as a conversation partner in human computer interaction enables us to consider what kind of conversation partners particular technologies might be and to design their interactional resources accordingly.

The recognition that computers act on the basis of resources within their situations, just as people act in accord with the resources of theirs, broadens our focus from the design of interfaces to the design of situations within which interaction between people and computers can occur. Instead of confining our attention to a narrow input/output exchange, we can think in terms of providing resources for the shared and negotiated meaning-making that makes mutual intelligibility possible in human computer interaction. Tools such as Suchman's framework enable us to investigate, design, evaluate and reflect on interaction design in terms of situational resources. We can consider what other kinds of resources may be part of both our and the machine's situations and include them in our design solutions. We suggest that these are precisely the kinds of tools and approaches we need to contribute to the design goals and commitments of Harrison et al.'s third paradigm of HCI, situated perspectives.

\section{ACKNOWLEDGEMENTS}

Our thanks to Astrid Larssen for her contributions to the Eyetoy ${ }^{\mathrm{TM}}$ study and to Tim Mansfield for his contributions to the Bystander project. Bystander was funded through the Australian Research Council Linkage Program. We are grateful to Lucy Suchman for her comments both on our use of her analytic framework and on the initial draft of this paper.

\section{REFERENCES}

Carroll, J. Situated Action in the Zeitgeist of HumanComputer Interaction. The Journal of the Learning Sciences 12, 2 (2003), 273-278.

Douglas, S. A. Conversational analysis and humancomputer interaction design, in Thomas, H, (ed) The social and interactional dimensions of humancomputer interfaces. Cambridge University Press (1995), 184-203.

Dourish, P. and Button, G. On "Technomethodology": Foundational relationships between Ethnomethodology and Systems Design, Human Computer Interaction 13, 4 (1998), 395-432.
Fitzpatrick, G., Kaplan, S. and Mansfield, T. Physical Spaces, Virtual Places and Social Worlds: A study of work in the virtual. In Proc. CSCW '96, ACM Press (1996), 334-343.

Frohlich, D. M. and Luff, P. Conversational Resources for Situated Action. In Proc CHI '89. ACM Press (1989), 253-258.

Harrison, S., Tatar, D., and Sengers, P. The three paradigms of HCI. In Alt. chi, Proc CHI '07. ACM Press (2006).

Hutchins, E. Cognition in the Wild. MIT Press (1995).

Koschman, T. Plans and Situated Actions: A RetroReview, The Journal of the Learning Sciences 12, 2 (2003), 257-258.

Larssen, A., Loke, L., Robertson, T. and Edwards, J. Movement as Input for Interaction - A Study and evaluation of Two Eyetoy ${ }^{\mathrm{TM}}$ Games In Proc. of OZCHI '04 (2004) ACM Digital Library

Loke, L. and Robertson, T. Design representations of moving bodies for interactive, motion-sensing spaces. International Journal of Human-Computer Studies, (2008a) http://dx.doi.org/10.1016/j.ijhcs.2008.11.003

Loke, L. and Robertson, T. Inventing and devising movement in the design of movement-based interactive systems. In Proc. of OZCHI '08 (2008b)

Loke L. and Robertson, T. Moving Bodies, Social Selves: Movement-Oriented Personas and Scenarios. In Proc. of OZCHI '05 (2005) ACM Digital Library.

Loke, L., Larssen, A. T., Robertson, T. and Edwards, J. Understanding Movement for Interaction Design: Frameworks and Approaches, Personal and Ubiquitous Computing 11, 8 (2007) pp. 691-700.

Merleau-Ponty, M. Phenomenology of Perception. Routledge (1962) [France, 1945].

Moran, T., Carroll, J., (eds). Design Rationale Concepts, Techniques, and Use, Lawrence Erlbaum (1996).

Plowman, L., Rogers, Y. and Ramage, M. What Are Workplace Studies For? In Proc. of ECSCW 95 (1995), 309-324.

Robertson, T., Mansfield, T and Loke, L. (2006) Designing an Immersive Environment for Public Use. In Proc PDC '06, ACM Press, pp. 31-40.

Robertson, T., Mansfield, T. and Loke, L. HumanCentred Design Issues For Immersive Media Spaces,. In Proc. of FUTUREGROUND 2004. Design Research Society (2004).

Suchman, L. Human-Machine Reconfigurations. Plans and Situated Actions, 2nd Edition, Cambridge University Press (2007).

Suchman, L. Plans and Situated Actions. Cambridge University Press (1987).

Vera, A. H. and Simon, H. A. Situated Action: A Symbolic Interpretation. Cognitive Science 7, 1 (1993), 7-48.

Wright, P., Blythe, M. and McCarthy, J. "User experience and the idea of design in HCI". Interactive Systems: 12th International Workshop. Lecture Notes in Computer Science Volume 3941 / 2006, 1-14 


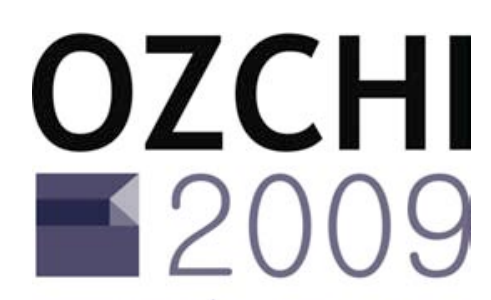

DESIGN | OPEN 24_7

OZCHI 2009, November 23-27, 2009, Melbourne, Australia.

Edited by Jesper Kjeldskov, Jeni Paay and Stephen Viller

Copyright the author(s) and CHISIG

Additional copies are available at the ACM Digital Library (http://portal.acm.org/dl.cfm)

or can be ordered from the CHISIG secretary (secretary@chisig.org)

ISBN: 978-1-60558-854-4 


\section{review process}

The OZCHI 2009 conference held in Melbourne, Australia 23-27 November 2009 received 60 long paper and 88 short paper submissions. From these submissions, 32 long and 42 short papers were selected to appear at the conference. All submitted long and short papers were subjected to double-blind peer review by an independent international reviewing committee of 131 people. Long and short papers were reviewed in their entirety by at least three peers. Industry case studies, panels, and workshop and tutorial proposals were reviewed by their respective co-chairs.

The OZCHI 2009 Proceedings is published by CHISIG and will be available from the ACM digital library shortly after the conference (http://portal.acm.org/dl.cfm). Additional copies can also be ordered from the CHISIG secretary (secretary@chisig.org)

\section{Conference and proceedings details}

The 21st Annual Conference of the Australian Computer-Human Interaction Special Interest Group, OZCHI 2009, 23-27 November 2009, Melbourne, Australia

Proceedings of OZCHI 2009 - Design: Open 24/7

Edited by Jesper Kjeldskov, Jeni Paay and Stephen Viller

Published by CHISIG, Melbourne, Australia (2009)

ISBN no 978-1-60558-854-4

\section{reviewers}

Alexander De Luca

Alexia Fry

Andreea Niculescu

Andrew Dekker

Andrew Vande Moere

Baki Kocaballi

Barney Dalgarno

Ben Kraal

Benjamin Close

Bernd Ploderer

Beryl Plimmer

Bharat Dave

Brendan Ryder

Bruce Thomas

Chao-Lung Lee

Christine Satchell

Christopher Lueg

Clint Heyer

Connor Graham

Daniel Salber

Danielle Wilde

Daryl Ku

David Ahlstrøm

David Jones

David Nichols

Dean Hargreaves

Dharani Perera-Schulz

Dimitrios Raptis

Duncan Stevenson

Elizabeth Kemp

Erik Champion

Flora Dilys Salim

Frank Maguire
Frank Vetere

Fraser Anderson

Gavin Sade

Gerry Gaffney

Gloria Gomez

Greg Wadley

Gregor McEwan

Guillaume Gibert

Hanif Baharin

Harald Holone

Hilal Al Maqbali

Hilary Davis

Holger Regenbrecht

Huanglingzi Liu

Hugh Macdonald

Hyewon Kim

Jan Seeburger

Jan Stage

Jane Li

Janne Jul Jensen

Jason Yang

Jeremy Yuille

Jeni Paay

Jesper Kjeldskov

Jo Vermeulen

John Grundy

John Murphy

Jolynna Sinanan

Jon Pearce

Jonas Fritsch

Julie Maitland

Kari-Jouko Räihä

Kasper Hornbæk
Kasper Løvborg Jensen

Keith Cheverst

Kenton O'Hara

Kim Halskov

Konstantinos Kazakos

Leila Alem

Lejla Vrazalic

Lian Loke

Linda Leung

Lorna Macdonald

Luc Julia

Marcus Foth

Margot Brereton

Maria Hakansson

Marianella Chamorro

Mark Billinghurst

Mark Gaved

Mark Rouncefield

Mark Toleman

Martin Brynskov

Martin Tomitsch

Masood Masoodian

Matthew Willis

Michael Pilling

Michelle Annett

Mikael B. Skov

Mike Broughton

Naisan Yazdani

Natalie Ebenreuter

Natasha Dwyer

Nick Taylor

Nilanthi Seneviratne

Nilma Perera
Pat Lehane

Patrick Watson

Penny Hagen

Peter Dalsgaard

Peter Jones

Ralf Muhlberger

Rene Hexel

Ricky Robinson

Rob Saunders

Ron van Schyndel

Saila Ovaska

Sandrine Balbo

Shawn Ashkanasy

Shiu Wen Wang

Silvia Fajardo-Flores

Sisira Adikari

Siu Man Carrie Lui

Sonja Pedell

Stefan Cronholm

Stefan Schutt

Steve Dillon

Supriya Singh

Susanne Tak

Syariffanor Hisham

Tek Yong Lim

Toni Robertson

Tuck Leong

Vesna Popovic

Victor Gonzalez

Vivienne Farrell

Wendy Hui

Yann Riche 